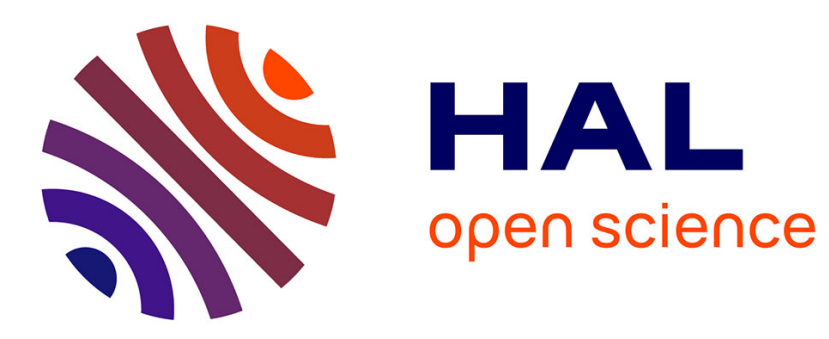

\title{
The Role of Discursive Information in Analyzing Multilingual Practices
}

Bettina Migge

\section{To cite this version:}

Bettina Migge. The Role of Discursive Information in Analyzing Multilingual Practices. Yakpo, Kofi \& Stell, Gerald. Code-Switching Between Structural and Sociolinguistic Perspectives, Mouton de Gruyter, pp.185-206, 2015, 978-3110343540. hal-01494571

\section{HAL Id: hal-01494571 \\ https://hal.science/hal-01494571}

Submitted on 24 Mar 2017

HAL is a multi-disciplinary open access archive for the deposit and dissemination of scientific research documents, whether they are published or not. The documents may come from teaching and research institutions in France or abroad, or from public or private research centers.
L'archive ouverte pluridisciplinaire HAL, est destinée au dépôt et à la diffusion de documents scientifiques de niveau recherche, publiés ou non, émanant des établissements d'enseignement et de recherche français ou étrangers, des laboratoires publics ou privés.

$$
\text { Copyright }
$$




\section{The Role of Discursive Information in Analyzing Multilingual Practices Migge Bettina}

Two broad lines of research have developed on code alternation or code-switching. One line focuses on structural issues related mostly to intra-sentential code-mixing and is based in formal syntactic and psycholinguistic approaches to language. The other line of research focuses on identifying the types of code-switching patterns, their social functions and meanings and the social motivations for code-switching. It applies methods of discourse and conversation analysis. Despite similar goals, these lines of investigation have proceeded separately without much cross-fertilization. The aim of this paper is to critically examine the main tenets of these approaches in the light of data from one contact setting involving related languages and to highlight ways in which the two approaches might complement each other. It argues that since codeswitching is an important meaning making resource, analysis of its functions should precede analysis of structural issues as the latter impact on the structure of codeswitching practices

\section{Introduction}

Lay people and educators have traditionally shunned the use of two or more languages within the same interaction or utterance arguing that it stems from speakers' lack of competence in one or all the languages involved. In an effort to 'combat' language mixing, educational institutions in particular have made use of several measures ranging from punishment to educational downgrading to assigning separate time slots or spaces to different languages. It is only in recent years, probably spurred by the widespread use of such practices in many domains such as the media, music, advertising etc. that opinions about code alternation practices have been improving. However, educators and educational institutions are only timidly adopting new approaches to multilingualism such as the Translanguaging approach (e.g. García 2009) that value people's multifaceted language competences and seek to build on them. Since code alternation practices challenge (structural) assumptions about the homogeneity of grammar and its independence from use, linguistic research has traditionally been concerned with understanding its workings, thereby seeking to legitimize its rightfulness.

Two broad lines of research have developed on code alternation. One deals with structural issues and the other is concerned with functional issues. Structural approaches to code alternation (e.g. Poplack and Meechan 1995; Muysken 2004; Myer-Scotton 1993b) are based on formal syntactic and psycholinguistic models and have been mostly concerned with identifying "the nature of the grammar underlying bilingual mixture." (Winford 2003: 126). Focusing on isolated instances of intra-sentential code-mixing usually involving clearly distinct languages, this line of investigation seeks to understand whether speakers rely on a single grammar or whether different grammars are at play, and how interaction between these different grammatical systems might be organized. Social or functional approaches to code alternation (e.g. Blom and Gumperz 1972; Myer-Scotton 1993a; Zentella 1994), by contrast, focus on identifying the types of code-switching patterns that exist, their social functions and meanings and the social motivations for code-switching. Using methods of discourse or conversation (Auer 1984) analysis, researchers have analyzed situated discourses involving a range of languages pairs. 
Although both research traditions share the same overarching goal - understanding the workings of code alternation practices - they have proceeded separately without much crossfertilization because they do not presently share the same methods of data collection and analytical frameworks. The aim of this chapter is to critically examine some of their main tenets and to highlight some areas where cross-fertilization would help to advance current knowledge. The paper argues that the two approaches are in fact complementary and should feed into each other. Greater attention to functional concerns in structural research on code alternation, for instance, would help to get a deeper understanding of the types of structural phenomena, their distribution and the constraints that govern their occurrence (see also Backus and Amuzu's papers in this volume for a discussion of related issues).

The data for this chapter come from recordings of situated interactions that were recorded in (western) French Guiana and Suriname involving mostly the closely-related English-based creoles Aluku, Ndyuka, Pamaka, that are collectively also referred to as Nengee or Eastern Maroon Creoles (EMC), and Sranantongo (SN) that originate from eastern Suriname. The paper considers both data from so-called native speakers who employ the languages as their main or only language of interaction and so-called non-native speakers who learned them later in life and only use them for some of their communicative needs.

Section 2 discusses some of the issues that arise in structural approaches to code-switching. Section 3 explores issues in social approaches to code-switching. Section 4 examines the findings and proposes an integrated approach to investigating instances of code-switching.

\section{Conceptualizing Code-Switching: A structural perspective}

From the perspective of structural research on code alternation or code-switching (CS) there are only two types of CS patterns, so-called inter-sentential and intra-sentential CS. They are differentiated based on where the switch occurs. In inter-sentential CS switches occur at clause or sentence boundaries: each sentence or clause comes from a different language. For instance, in (1) the first clause is entirely in English while the second one is entirely in Spanish.

(1) It's not the same you know, no e(-s) como acá. (English-Spanish)

'It's not the same you know, it's not like her.' (Zentella 1994: 99)

Intra-sentential CS, by contrast, is broadly defined as involving insertion of single elements or phrasal entities from one language into the morpho-syntactic frame or sentence structure of another language. In (2) the French noun blague is integrated into a structure that is entirely in Kali'na.

(2) blague-mempo wa. (Kali'na-French)

joke-little.person be

'I'm a little commedian.' (Alby and Migge 2007: 54)

Based on the tacit assumption that the two types of CS can be easily separated, structural research has focused on intra-sentential CS because it "produces various kinds of hybrid structures that 
require explanation." (Winford 2003: 126). ${ }^{1}$ Discussion of these hybrid structures has been concerned with issues such as the identification of the morpho-syntactic frame of these structures and the types of elements that may be involved in CS and the rules that govern their occurrence. I discuss each in turn.

\section{1. Classifying instance of intra-sentential CS}

While there are cases of congruent lexicalization (Muysken 2004) where two (or more) languages "share a similar structure which can be filled lexically with elements from either language", current structural approaches to CS such as the Matrix Language Model (MLF; Myers-Scotton 1993a) generally operate on the assumption that mixed utterances consist of a main or matrix language and a subordinate or embedded language. The matrix language (ML) provides the grammatical frame of a sentence, namely the morpheme order principles, rules and the function or system morphemes. Additionally, the ML generally also contributes most of the content morphemes. The embedded language (EL), by contrast, provides single content morphemes that are integrated into the ML frame. Thus, in the case of example (2), Kali'na is the matrix language while French is the embedded language as it only provides a single element, a morpheme. There are also structures where an entire phrase or island, in the words of Myers-Scotton (1993b), comes from the embedded language. In (3), for example, the French noun phrase la feuille forms an island in a Kali'na structure in that it consists of more than one French item and the rules that govern their combination also come from French rather than Kali'na.

(3) Ami la feuille se wa. (Kali'na-French)

'I want the piece of paper.' (Alby and Migge 2007: 54)

It has been notoriously difficult to establish precise criteria for identifying the ML and the EL in any given case. Myers-Scotton (1993a: 68) argues that the language that provides the greater number of morphemes in a discourse sample typically also functions as the ML. However, in some cases this criterion might be too crude as it is possible that one or more changes in ML/EL take place throughout the discourse (Nortier 1990: 158). People might start out in one language and then continue in another language (or in what could be called a mixed code). Take for instance the example in (4). Here the speaker produces an entire sentence in Dutch and only uses the Eastern Maroon or Nengee affirmative marker eyee as an assertive particle at the end of the sentence. The following sentence is entirely in the Eastern Maroon Creole apart from the word frank which is best classed as a borrowing from Dutch.

(4) Maar ik heb geen waarde aan jou, eyee. Pe mi meki

but I have NEG worth of you yes where I make

wan dunsu frank wan dey, da i e meki...

DET 1000 francs DET day then you IMPF make

'But I don't gain anything from you, yes. When I make one thousand francs

\footnotetext{
${ }^{1}$ However, the two kinds of CS also appear side-by-side either within the same interactional context or across different ones (Pandit 1990, Paff 1979, as cited in Winford 2003: 164-5), see also section 3.
} 
a day, then you want me to...'

Note: italics: Dutch; bold: Eastern Maroon Creoles

But even if we pay attention to the sentence or utterance level and simply count the words in a sentence, it is often difficult to establish the makeup of the ML. Take for instance example (5) from the French Guianese corpus involving contact between Nengee and Sranantongo in the speech of a Pamaka man.

(5) A sani dati, I kan taagien taki a tori dati mu skotu a mu kii en. DET thing DEM you MOD tell him say DET story DEM must end s/he MOD kill it 'That thing, you can tell him that issue must end, he should stop it.'

Note: regular: shared EM/SN elements

In (5) four words (underlined) are clearly identifiable as belonging to Nengee, five words (bold) are associated with Sranantongo and eight words (regular) are best described as being shared between the two. It seems unsatisfactory to claim that Sranantongo is the ML of (5) simply on account of the fact that there is one more distinctive Sranantongo than Nengee word in this sentence. Since the notion of the ML is heavily dependent on the idea of function morphemes and grammatical rules and principles, categorization could also focus on these two aspects. However, this still does not provide much more certainty because all the structural principles and a total of six function morphemes (a: DET.sg (2); a: 3sg.sbj (1); en: 3sg.obj (2) i:2sg.sbj (1)) are shared, three are from Sranantongo (dati: distal demonstrative modifier (2); kan: weak obligation (1)) and one is linked to Nengee ( $m u$ : strong obligation (1)).

In addition to difficulties with applying a simple counting procedure for making decisions about the ML, there is also the issue of elements that do not appear to belong to either Nengee or Sranantongo. Such items are intermediate between Sranantongo and Nengee and thus cannot be easily assigned to either nor are they on a par with what I have so far called shared elements, i.e. elements that are found in both languages. Table 1 gives a few common examples from the corpus.

Table 1. Forms that are intermediate between Nengee and Sranantongo

\begin{tabular}{|l|l|l|l|}
\hline Form & Gloss & Nengee Form & Sranantongo Form \\
\hline dape & there & ape & drape \\
\hline pliti & split & piiti & priti \\
\hline planga & planks & paanga & pranga \\
\hline heli & whole & hii & heri \\
\hline
\end{tabular}

Elements from other languages such as Dutch, French and English in particular are equally difficult to classify as it is not always clear whether they are in fact borrowings in either or both of the two languages or whether they are independent insertions. In example (6a) the word pickup could probably be classified as a borrowing from English as it is used in (certain styles of) Nengee and Sranantongo. However, based on its phonology and the fact that it is also used in Dutch, it might also be classified as a borrowing from Dutch. The case is even more complicated with respect to tweede, nooit and rei in (6b). All three of them have Nengee and/or Sranantongo alternatives that are 
also still being used, however to different degrees. While rei appears to be the main form to express the notion of 'drive' in Sranantongo, ley and waka are still commonly used in varieties of Nengee. Nooit also derives from Dutch and is also common in Sranantongo; its integrated from noiti occurs in both Sranantongo and Nengee but is much more common in Nengee. ${ }^{2}$ Finally, tweede is clearly Dutch but also widely used in urban Sranantongo, while in Nengee the form taa one 'other one' is also common. This suggests that in (6b) all three words could be classified either as being part of Sranantongo or as separate insertions from Dutch.

(6) a. Na wan Toyota pickup.

FOC DET Toyota pickup.car

'It is a Toyota pickup.'

b. B, da i no poti a tweede wan? Nooit a e rij.

$B$ then you NEG put DET second one never it IMP drive

'B, did you not repair the second one? It never works.'

Given that these kinds of structures are rather frequent in the corpus, it seems better to postulate the existence of a shared or separate frame which can be filled with elements shared by Sranantongo and Nengee, elements from other languages (i.e. Dutch), in-between elements (Table 1) and distinctive elements from different languages. Viewed from this perspective, only structures that involve predominantly Nengee (7a) or Sranantongo (7b) elements and/or are governed by principles that are distinctive of one or the other language would then count as belonging to either of these languages.

(7) a. Den taa man ya án sabi wooko anga en.

DET other man here NEG know work with him

'These other men don't know how to work with him.'

b. ay, eyee, den presi dati tof yere.

yes yes DET place DEM difficult ASSERT

'Yes, yes, those places are difficult!'

Other structures such as (5 and 6) would then constitute a separate category which is neither Nengee or Sranantongo, but a bilingual or multilingual code. Social evidence in favor of such a triparte distinction comes from research on social identities and language use among Maroons (Migge 2007, 2011; Migge and Leglise 2011, 2013). It shows that younger Maroon men in particular closely identify with being Maroon as opposed to members of the Afro-Surinamese creole population who are ideologically linked to Sranantongo. However, having been stigmatized as backwards, younger Maroons are also at pains to display that they are urban and modern. In order to negotiate these two aspects in their self-presentation - being Maroon but having modern sophistication - Maroons creatively combine aspects from both realms. That is, they create a 'third'

${ }^{2}$ One of the reviewers suggests that nooit is considered Dutch if it occurs in sentence-final position without a final /-i/. However, Sranantongo noiti and Dutch nooit are indistinguishable in midsentence because, Sranantongo tends to elided final vowels in non-final position. 
way of being that is fuzzy from the point of view of traditional ways of categorizing people and languages. They combine aspects from Nengee and Sranantongo (culture and language), and increasingly also from other languages such as Dutch and French that are also marked as urban, modern and 'being part of the wider world', to display their multiple connections and, more crucially, to avoid being identified with (negative stereotypes of) either. This fuzzy style is particularly common in interactions among young(er) men who are socio-culturally most closely identified with the world beyond the local networks and community. It is an important feature that traditionally distinguishes them from elders and women and thus its use makes a claim to membership in this category. It is also used in other contexts such as in conflicts with elders and flirtation, where status negotiation is at play. This then suggest that in order to determine the ML or EL of a given structure, we not only require a broad understanding of the overall social context (i.e. what kinds of modes of being and identities exist), but we must also know the types of practices (monolingual codes, mixed codes) that are part of the local sociolinguistic economy, their broad associations, characteristics and functions. This kind of information is important for distinguishing types of CS patterns that are similar on the surface but functionally different and thus are likely to be governed by different (structural) constraints.

\section{2. Elements in intra-sentential code-switching}

Structural approaches to CS, like Myer-Scotton's MLF model, posit that the ML provides all the system or function morphenes while the EL only contributes content morphemes. Not being structurally heavily bound, content morphemes such as verbs, nouns and adjectives can be freely switched between languages. By contrast, switching of system or function morphemes is subject to special constraints because it requires a certain amount of (perceived) congruence between the structural systems in contact. System morphemes belong to a closed class involving a range of elements such as tense, mood and aspect markers, quantifiers, inflectional morphology etc. (see Myers-Scotton 1993a: 101 for a list of elements). ${ }^{3}$ The only exceptions to this stipulation are cases where the morphology of both the ML and EL are used on the same element, so-called cases of double morphology, and so-called EL islands, where whole phrases from the EL that contain function elements are inserted into the ML. The examples in (8) illustrate the typical distribution of the ML and EL forms. The function morphemes and most of the content morphemes are from one language and only one content morpheme - a noun (8a) and a verb (8b) - comes from another language or is distinctive. (8a) comes from a discussion carried out in the Eastern Maroon variety Pamaka; only the word prijs clearly derives from Dutch. (8b) comes from the same discussion and could be described as involving an insertion from Sranantongo, namely wroko. ${ }^{4}$

(8) a. Mi gi i wan prijs kaba.

I give you DET price already

'I gave you the price already.'

\footnotetext{
${ }^{3}$ Note, however, that the distinction between function and content morphemes is not always that clear (Winford 2003: 115).

${ }^{4}$ Alternatively, (8b) could also be interpreted as involving a shared Sranantongo/Eastern Maroon frame with a distinctive element from Sranantongo.
} 
$\begin{array}{rlll}\text { b. Ma ala faya e } & \text { wroko? } \\ \text { but all light imp work }\end{array}$

'All the car lights are working?'

Besides these classic examples, there are also examples of EL islands. Example (9a) follows the structural principles of both Nengee and Sranantongo and all the morphemes except la PAF come from these two languages. $L a$ PAF is best described as a French island that has been inserted into the shared Nengee and Sranantongo ML frame. It only consists of elements from French which are also combined using structural principles from French - note that the latter happen to overlap with those of the ML, however, in Nengee and Sranantongo nouns in this position would only be preceded by a determinier under certain conditions. There are also examples where the structural principles of the EL island only conform to those of the EL. In (9b) the structural makeup of the sentence follows Nengee and Sranantongo rules, however, the order of words in the EL island carte grise follows that of French as the adjective follows the noun. ${ }^{5}$

(9) a. Mi miti wan man na la PAF.

I meet DET man LOC DET PAF

'I met someone at the PAF.'

b. Carte grise de?

card grey exist

'Insurance papers are there?'

Analysis of the data from French Guiana show that content morphemes and EL island are not necessarily the most commonly used distinctive elements though. As illustreated in the examples in (10), function morphemes play an important role too.

(10) a. Luku wan tra wagi fadon uit.

Look DET other car fall out

'Look another car fell off the jack.'

b. Sranan ná abi den wagi disi.

Suriname NEG have DET car DEM

'Suriname does not have these kinds of cars.'

c. A no bun yere!

it NEG good ASSERT

'It isn't good!'

d. Meti nanga pinda tok.

meat with peanuts right

'Meat with peanuts, right.'

\footnotetext{
${ }^{5}$ Unfortunately, the corpus only included instances that could be seen as partially holophrasitic, but observation also 'produced' the following example Gi mi a pantalon bleu di de a ini i saka. 'Give me the blue pair of trousers that are in your bag.' which involves the same ordering of noun and adjective as in (9b).
} 
e. Mi kan ley tu trip i ferstan tok.

I MOD drive two trip you understand right

'I can make two trips, you understand, right.'

f. A man ya, a wan man di ben sooto tok.

DET man DEM FOC DET man REL PAST lock right

'This guy, he was locked up, right.'

While the data involve few function morphemes from European languages, some such as uit (10a) do nevertheless occur outside of so-called EL islands. ${ }^{6}$ What is, however, striking is the fact that alternation between function morphemes such as the negation marker (EM án/ná - SN no), some modality markers such as the obligation marker (EM $m u$ - SN musu), the potential modality marker (EM sa - SN kan) (Migge and Winford 2009), the relative marker (EM di - SN san), the committative preposition (EM anga - SN nanga) are commonly used besides discourse markers (tok; EM yee - SN yere) and phono-lexical features such as the alternation of long vowels with an $\mathrm{rV}$ sequence (EM wooko - SN wroko) or the variation between /l/ and /r/ (EM leli - SN leri 'learn') in code alternation practices. That is, speakers do not only draw on content morphemes, but also code-switch system morphemes and these system morphemes are not typically part of EL islands as predicted by MyerScotton (1993b). ${ }^{7}$ This is of course facilitated by similarities in structure between Nengee and Sranantongo, but it is not clear that typology is the only driving force. It also points to the fact that speakers, unlike linguists, do not systematically distinguish between content and function morphemes or focus on content morphemes only, as implied by structural models. Rather, in their efforts to create distinctive patterns (i.e. to encode social and interactional meaning), speakers simply focus on areas or elements where alternate forms exist without regard to their lexical status. ${ }^{8}$ The amount of elements that are made salient depends on the context and communicative intent, i.e. whether the speaker wants to be fuzzy or align with a particular language, see below.

\subsection{Conclusion}

The discussion suggests that while structural research on CS has much advanced our knowledge about these kinds of hybrid structures, there are still a number of issues that appear to be difficult to resolve by solely relying on structural methods of data collection and analysis. While it is important to distinguish the kinds of systems that are involved in instances of CS, reliance on structural criteria such as word counts alone are problematic because it is difficult to determine indicative cut-off points or how to deal with shared or intermediate forms especially in the case of closely related languages. Speakers do not differentiate varieties or languages on structural grounds

\footnotetext{
${ }^{6}$ Note that the use of uit in this sentence does not function in the same way as in Dutch. In Dutch it either functions as a preposition or as a prepositional or separable affix. In Surinamese languages uit always appears in post-verbal position. In this sentence is seems to be parallel to a result-expressing serial verb SN trowe/ EM towe.

${ }^{7}$ See also Bentahila and Davies (1983: 315) for a discussion of this and related issues in relation to Arabic and French CS.

${ }^{8}$ One area that has not received attention is this regard is the area of intonation which could be of particular importance especially in the case of closely related languages.
} 
or apply frequency counts. Instead, issues of salience - what is considered to be distinctive of a given variety/language - and their presence or absence tend to play a more important role in choosing material from one or the other language. It is therefore vital that CS research starts out with an assessment of the broader sociolinguistic context. Based on the perspective of all social actors in the setting, we need to establish the sociolinguistic structure of the setting such as the number of varieties/languages that are recognized, their distribution and their distinctive features, before making judgments about the systems in interaction. This needs to take account of the fact that linguists' views of what constitutes a language or a system might be quite different from speakers' views. For instance, research has spent much ink on arguing for the different role of content and function morphemes in CS, however, data from French Guiana suggest that this distinction does not play an important role in the code-switched productions that emerge in this context where speakers use closely related language varieties. ${ }^{9}$ Speakers regularly draw on both function and content morphemes (outside of so-called islands) in their production of such patterns. Detailed understanding of speakers' conceptualizations of varieties, i.e. what they consider to be emblemic, and their relationships in a given context and across settings might shed light on the importance and this distinction.

Structural research on CS has made some headway in providing insights into the principles and rules that govern CS patterns, but accounts fall short of explaining the factors that promote CS in general and the occurrence of the two types of CS patterns that they posit. In addition, there is a tacit assumption that there are only these two types of CS patterns and that they do not have an internal structure. In the next section I will take up these issues in more detail by looking at sociolinguistic approaches to CS.

\section{Conceptualizing Code-Switching: A qualitative perspective}

In contrast to structural research, sociolinguistically oriented work on CS has focused on establishing the types of CS patterns that exist and explored the functions and motivations for CS as well as the relationship between types and functions. While researchers in the area agree that there are several kinds of CS patterns (see below) beyond the two posited by structural research insertional and alternational CS - and that there are important linkages between CS patterns, functions and settings, there is disagreement about the nature of these linkages and ways of examining them.

\section{1. Socially-oriented model of code-switching}

One of the socially oriented approaches to CS is Myers-Scotton's (1993a) Markedness Model. It is based on the insights of Blom and Gumperz's (1972) study of CS in Hemnes, Norway, which argued that alternation between codes has social significance - it conveys a change in the extralinguistic context (situational switching) or functions to assign meaning to an utterance (metaphorical or conversational switching). The basic premise of the Markedness Model is that speakers' code

\footnotetext{
${ }^{9}$ While there is a fair amount of structural and morphemic overlap between Nengee and Sranantongo, there are also important differences. It is on these differences that people focus when code-switching to create interactional meanings. Note also that speakers are generally dominant in one or the other variety and only have varying degrees of knowledge of the other.
} 
choices are strategic and goal-oriented, being determined by speakers' interactional goals and the interaction's social characteristics, including both the extralinguistic nature of the interaction and the speech economy of the community and the setting. CS 'exploits the socio-psychological attributes that languages assume in a specific community, based on its patterns of language use' (Myers-Scotton 1993a: 3). The social motivations for CS are determined by the relative social markedness of codes in an interaction. ${ }^{10}$ Each code indexes a specific kind of social relationship, including participants' attitudes and expectations to each other, the so-called rights and obligation (RO) set. The model posits that for each interaction, there are (relatively) marked and unmarked choices. Unmarked choices are considered relatively habitual, common or expected and employ the main or most typical medium for a given interaction, symbolizing the most typical RO set for a given interaction. Marked choices, by contrast, make use of non-typical or 'embedded' codes, are relatively rare and unexpected and are interpreted as a departure from the normative code and RO set for the interaction. They are 'a negotiation about the speaker's persona (who the speaker is) and the speaker's relation to other participants' (Myers-Scotton 2006: 160). Speakers select marked or unmarked codes based on considerations of communicative effectiveness, i.e., which choices will maximize interactional rewards and minimize interactional costs. Essentially, CS is 'a meta-message of conversational moves' and functions to negotiate 'speakers' perceptions of themselves and their relations with others' (Myers-Scotton 1993a: 111).

The Markedness Model posits four types of CS. Each one occurs in a different kind of social situation, indexes a distinct self-image of the speaker and his/her view of the relationship between interlocutors (RO set). Code-switching as a sequence of unmarked choices also referred to as sequential unmarked code-switching occurs when situational factors such as the topic, the participants or the narrative framework change during an interaction causing a change in the RO set. In order to index the new RO set and, more crucially, its acceptance, interlocutors change their interactional code. By contrast, code-switching itself as the unmarked choice or unmarked code-switching refers to a situation in which speakers frequently switch between two or more languages in the same interaction. This could involve both insertional and/or alternational switches. It differs from the other CS types in that 'each switch [...] does not necessarily have a special indexicality; rather, it is the overall pattern which carries the communicative intention' (Myers-Scotton 1993a: 117). It is found in situations in which an ethnic language is highly valued but coexists with another language used for status-raising activities. Interlocutors are generally members of a common peer group and wish to actively invoke their alignment with the two social worlds that these two codes index; it is a way of making aspects of these two worlds salient. The third type she refers to as Code-switching as a marked choice. It occurs when the speaker selects a code that is seen as a marked choice in the interaction. It signals the speaker's lack of agreement with the expected RO set and their attempt to negotiate a new RO set. Finally, code-switching as an exploratory choice occurs when uncertainty exists about the appropriate $\mathrm{RO}$ set for the situation. Interlocutors will then switch between different codes that they share and thereby offer different RO sets until they find one on which they can both agree.

Auer $(1984,1995)$ equally focuses on determining the social meanings and functions of CS.

${ }^{10}[\mathrm{~S}]$ peakers have a sense of markedness regarding available linguistic codes for any interaction, but choose their codes based on the persona and/or relation with others which they wish to have in place' (Myers-Scotton 1993a: 75) 
However, his approach, which is based in conversational analysis, posits that it is the juxtaposition of two or more codes that has signaling power rather than the languages involved or the directionality of change. While each language is arguably linked to particular social meanings, settings and activities, this association is probabilistic rather than absolute. He argues that like gesture and intonation, CS functions as a contextualization cue. It does not have a fixed referential meaning, but makes relevant "some aspects of the context which, in turn, is responsible for the interpretation of an utterance in its particular locus of occurrence." (Auer 1995: 123). This means that the meaning of CS, like that of other contextualization cues, is derived at through a process of context-sensitive inferencing that has to be investigated separately for each instance of CS. There are two ways in which inferencing generates meaning. CS either creates a contrast to what went on before, indicating otherness such as lack of agreement or difference in voice, for instance. Or, in addition to signaling otherness, CS, like other contextualization cues, also restricts the number of possible inferences "because cues may have (received) an inherent meaning potential due to conventionalization or frequency of use of the pattern" (Auer 1995: 124). According to Auer (1995: 124), CS also has its own characteristics because "the situated interpretation of code-alternation as a contextualization cue is strongly related to the sequential patterns of language choice."

He distinguishes four patterns. The first one represents the case whereby an established language-of-interaction, A, for a certain context is at some point during the interaction switched to language B during turn transition from speaker 2 to speaker 1 (Ia) or within one turn (Ib). The switch in language-of-interaction is accepted by the interlocutor(s) and the conversation continues in language B. Patterns Ia and b contextualize a change in the characteristics of the interaction such as a change in conversational activity, topic, mode or participants. They are equivalent to MyersScotton's (1993a) sequential unmarked code-switching.

Pattern Ia: A1 A2 A1 A2//B1 B2 B1 B2

Pattern Ib: A1 A2 A1 A2 A1//B1 B2 B1 B2

A second pattern also referred to as language negotiation involves the use of different languages by the interlocutors. Either such a pattern of language alternation persists (IIa) or is resolved in favor of one of the languages at some point during the interaction (IIb). Patterns II signal speaker preference such as in terms of broad political considerations or issues of language competence. They are similar to Myers-Scotton's (1993a) code-switching as an exploratory choice and marked codeswitching though her definition carries a stronger assumption that interlocutors aim towards resolving language choice in favor of one language.

Pattern IIa: A1 B2 A1 B2 A1 B2 A1 B2

Pattern IIb: A1 B2 A1 B2 A1//A2 A1 A2 A1

The third pattern involves CS within single turns that defies clear establishment of a language-ofinteraction. The internal switches, or at least some of them, may have indexicality, but do not need to. In the latter case, they provide insights into how people view the situation and into how speakers want to position themselves, and are thus both discourse- and participant-related. Interlocutors may either decide to carry out the interaction in this mixed mode (IIIa) or adopt one 
of the two languages (IIIb).

Pattern IIIa: AB1 AB2 AB1 AB2

Pattern IIIb: AB1//A2 A1 A2

Pattern IV involves insertion of single words or phrases from language A into a turn otherwise carried out in language B. Auer refers to this momentary departure from the language-ofinteraction as transfer and argues that it can be discourse- and participant-related in that it may contextualize a particular interactional frame or a person's language competence. Patterns IIIa and IV are similar to unmarked code-switching in Myers-Scotton's (1993a) categorization.

Pattern IV: A1[B1]A1

The discussion suggests that there are important similarities between the two models. Crucially, both models posit that there are several CS patterns. a's approach posits a relatively close linkage between the type of pattern and its social and interactional functions as well as its interpretative approach is heavily dependent on the sociolinguistic meanings of the languages involved. In contrast, Auer's approach posits a much less fixed linkage arguing that meanings have to be carefully defined using a sequential analysis of interactional choices. The same pattern may simultaneously and/or depending on the interaction perform several functions.

\section{2. Code-switching in the data from French Guiana and Suriname}

One aspect that is very striking about the data from French Guiana and Suriname is the fact that there do not appear to be clear instances of patterns I and IIa and b. Much of the data resembles patterns IIIa or IV in that there is alternation between elements from two or more languages, including shared forms, within and across turns. Take Extract (1):

Extract (1)

1 B: Da na yu meki a wagi! 'Thus, you repaired the car!'

2 D: Aai 'Yes'

3 B: Da yu na, na international, jon. Da mi o bay wan broko wagi, jon.

'Then you are international, man. Then I'll buy a broken car, man.'

4 D: P, i si, i si a wagi disi? 'P, do you see this car?'

5 P: $\mathrm{mhmm}$

6 D: I sabi a wagi fu mi? San na a wagi disi. 'You know my car?

What kind of car is this one?'

7 P: Na wan pikup, a wan Toyota pikup. 'It is a pickup, a Toyota Pickup.'

8 D: Da i no sabi ala den wagi fu mi. 'Then you don't know all of my cars.'

9 P: No na dati wan nomo. 'No, only this one.'

$10 \mathrm{~B}$ : A frustu se wan. 'The ??'

11 D: No wakti, mi a wan 306 ete. 'Hold one, I also have a 306.'

12 B: Ehmm

13 D: Fu di mi e waka anga futu. 'When I'm walking.' 
$14 \mathrm{~B}: \mathrm{Da}$ i e waka anga futu ete, jon brudu jon.

'Thus you are still walking, man really.'

15 D: No, mi mag, eyee mi o ka fini. BL, BL, da i no poti a tweede wan nooit a, a i rey?

Ya tok, ef i no poti a souda nooit a, a i rey, na mi na a souda.

'No, I am allowed to, yes, I can stop. BL so you have never yet used the

second one. Does it work? Yes, ok, if you never use the Souda, it will never

work. I want the Souda car.'

italics: Sranantongo; bold: Nengee; italics/underlined: Dutch; bold/underlined: French Guianese Creole; roman: shared Nengee \& Sranantongo

In Extract (1) several younger men interact in a local bar in Saint-Laurent-du-Maroni. There are no turns that can be unambiguously assigned to just one language. Most of the turns involve alternation between shared Nengee and Sranantongo forms and distinctive ones coming from either of the two languages or other languages such as French Guianese Creole or Dutch. Extract (1) is a case of what has been described as transfer (Auer) or unmarked CS (Myers-Scotton) in that switches mostly involve individual words and each switch does not appear to have a special indexicality. Instead, it is the overall pattern that is of interest. It is a case of participant-related switching because speakers essentially display their diverse linguistic competence to each other, a crucial feature of peer-group behavior among them as it signals urban sophistication (Migge 2007).

However, not all instances of what appears to be CS are in fact an instance of CS. Take for instance Extract (2) which was delivered by a man from Guyana who was conversing with a Maroon man who is roughly from the same age range (late 30 s to mid $40 \mathrm{~s}$ ).

\section{Extract (2)}

Dede of dede wo broko a basis yere, tru efu i no wani taki, i mu denki taki moro gaan bigi basis fu Europe dya tok, da a kondre nooit i si taki a kondre abi wan bun waarder tok. A kondre no abi wan bun waarder di seti, fosi den wetman seti wan bunbun waarder na a kondre. I sabi san den man e du?

'Even if there are fatalities, we will destroy the European Space centre [in Kourou], right, honestly, if you don't want to talk, you should remember that the biggest space centre of Europe is here, right, but this country never, you never see that they value the country properly, right. The country does not have a value on its own outside of the value that the Europeans have brought to the country. You know what they did?'

italics: Sranantongo; bold: Nengee; italics/underlined: Dutch; bold/underlined: French; roman: shared Nengee \& Sranantongo

Taking a language perspective, we see that there are elements that originate from different linguistic sources such as Nengee, French, Dutch, Sranantongo and shared Sranantongo/Nengee forms. The overall pattern closely resembles that in Extract (1). The main difference, however, is that while this kind of mixed code is only one of the styles that the interlocutors in Extract (1) do in certain kinds of interactions, this is the main or only way that many non-Maroon interlocutors speak. The latter are often either not fully aware that their way of speaking involves insertions from several languages or they assume that this is the way to speak Nengee or what is often referred to as Takitaki in French Guiana because their main interlocutors, the Maroons of this age group, typically 
speak like that in public out-group settings (Migge and Léglise 2013). Extract (2) is best described as a case of dialect convergence.

However, as pointed out by Auer (1995: 131-2), this kind of alternation may also have indexicality and perform both participant- and discourse-related functions. In Extract (3), a woman in her early 40 s is explaining language practices to the author and another European friend of hers.

\section{Extract (3)}

1 Bs: ma a wakaman taal teki fesi hem, a wensi i go na Paramaribo, i e si taki a

2 Sranan sei, i e si taki na soso wakaman taal_den man e puur kon, den

3 man e tak' in code, den man e fringi tek' i!

'but the wakaman language has become most important, even when you go to Paramaribo, you see that on the Surinamese side, you see that it's only wakaman language they are pulling out, they are speaking in disguised form, they are throwing it at you.'

In this conversation, Bs is clearly at pains to display her linguistic versatility by alternating shared Sranantongo/Nengee elements with ones that originate from Dutch (taal 'language'), nonSranantongo/Nengee (Paramaribo) or Sranantongo (Sranan sey 'Suriname'). This kind of alternation is very fluid, not involving hesitation. However, her alternation towards the end of line (2) and in line (3) between shared and Sranantongo elements is discourse-related. She is using parallelism to create a climax in her description of wakaman taki, a style of Sranantongo. The carrier phrase is realized using shared Sranantongo/Nengee forms, but the descriptive part is clearly set off in the Sranantongo style that is being described and through special emphasis. This voicing assigns authority to the description.

Extract (4) comes from the same context as Extract (1). While these men commonly draw on CS transfer or unmarked CS - to display their linguistic versatility (e.g. Extract 1), CS is also used to distinguish different parts of the discourse or activities. In line (1) $\mathrm{Br}$ is imagining what he will do and get during a hunting trip in a somewhat dreamy way. This is done using mostly shared Sranantongo/Nengee and Nengee forms. This saliently contrasts with Pe's turn in lines (2-4) that predominantly consists of shared and Sranantongo forms and employs a somewhat creaky voice quality that is commonly associated with urban (younger) male speech. This shift negotiates Pe's irritation with Br's inability to seriously engage with the organization of the hunting trip. This suggests that variation in the relative amount and type of insertions may contextualize a change in discourse activity (dreamy speech versus complaining) and a difference in self-representation in that Pe distances himself from Br's dreamy behavior, claiming a more authorative self.

\section{Extract (4)}

1 BR: Ya tok ma mi, den fisi ${ }^{11}$ di mi o kisi dape, den o tyahipi en mi na fisi mi e go suku.

'Ok, but I, the fish that I will catch there, they'll be a lot and as for me, it's fish that I'm searching for.'

\footnotetext{
${ }^{11}$ The word fisi (but also kisi) followed Eastern Maroon pronunciation [ $\mathrm{f} f \mathrm{j}$ ] rather than Sranantongo phonological patterns [fisi].
} 
2 PE: I ne e ferstan san mi e du now. Mi kan rey tu trip, i ferstan tok, mi kan ley tu trip.

3 Mi e ley den man fu mi. Efu yu no kba, a yur di i o kba, i e gi mi so wan yuru i o kba,

$4 \quad$ i sabi tok. Mi e teki yu tapu a yuru fi i, i sabi tok...

'You don't understand what I'm doing now, I can do two trips, you understand right, I can do two trips. I drive my guys. If you are not ready, the time when you are ready, you give me a specific time when you'll be ready, you know. I come and take you at the time you want to, you know right...' (Migge and Léglise 2013: 277)

Structuring also occurs at the level of lexical choices. Interlocutors may draw on 'mundane' forms that are commonly known or traditional or 'racy' forms that have modern or subcultural overtones and thereby create different social identities (Spitulnik 1999) and different kinds of relationships. Compare, for instance, Extracts (1) and (5). In Extract (1), the interlocutors draw on elements from several languages and several of them (international, tweede, tok, ya tok, I sabi tok) have become associated with young men's in-group speech. ${ }^{12}$ Interactions involving these kinds of forms invoke young men's life worlds and position their users as members of that in-group. By contrast, Extract (5), which comes from an interaction between titled elders at the end of a fairly formal interaction, involves only mundane forms from Sranantongo that contrast with Nengee and shared elements in lines (4-5). The insertions assign a Sranantongo reading to the turn, negotiating a (momentary) shift away from the relatively formal relationship that typically exists between the two elders. Interactionally, it functions to convey that the request to talk to the author is harmless (i.e. does not involve a marriage proposal).

\section{Extract (5)}

1 Anton: Ma, daaa, fa de e kai a flou nen? 'But, so what's the woman's name?'

2 Bettina: Bettina!

3 Anton: Soo Betna. (.) 'Okay, Bettina.'

4 (to $\mathrm{O}$, another Kabiten) So, da (.) kabiten, mi kan taki ptyin tori anga a uman pikinso

5 'yere? A nowan mulikimuliki toli.

'Okay, well kabiten, can I chat a little bit.'with the woman, right? It's nothing

bothersome.'

60 : (nods approvingly and laughs)

7 O: Iya, iya papa! 'Yes, yes elder!' (Migge 2007: 103)

\section{Conclusion: Towards an empirically adequate approach to CS}

The discussion suggested that while structural approaches to CS have highlighted important principles about the patterning of CS, most of the principles and assumptions that have been proposed over the years have turned out to be problematic upon closer empirical inspection. While it is intuitively right to assume that CS involves juxtaposition of two or more codes, their identification and determination of their respective roles in the juxtaposition is far from

\footnotetext{
${ }^{12}$ It is not entirely clear whether the Dutch-marked forms should be considered as insertion from Dutch or as Dutch borrowings in Sranantongo/Nengee. More than likely, this differs among speakers.
} 
uncontroversial. There are no adequate measures that can be applied across the board to unambiguously determine whether a language functions as the matrix language or as the embedded language, or whether we are dealing with a case of dialect convergence. Word counts run into problems because there are not clear-cut off points and because simple word counts cannot take adequate account of structural features such as word order. General assumptions about the social appropriateness of a given language in a particular setting are problematic because associations between language and social settings are rarely stable over time or across speakers; they can function at best as broad guidelines. The functions of languages may also change within the same interactional context. It may also simply be difficult to distinguish varieties/languages on structural grounds alone because forms cannot be easily assigned to one or the other language or because mixed codes have developed that defy easy lexico-structural identification. Moreover, while content morphemes clearly play an important role in CS patterns because their lack of structural boundedness facilitates interlingual identification, this does not mean that function morphemes have no role to play in CS. In fact, particularly in the case of closely related languages function morphemes may be strategically deployed for negotiating patterns of distinction. Finally, while both structurally and sociolinguistically-oriented research have identified different kinds of CS patterns, neither set of patterns (insertional versus alternational; 4 basic patterns) exhausts the kinds of tactics (e.g. variation in frequency of distinctive vs. fuzzy forms, use of racy vs. mundane forms ) that bilinguals make use of for contextualizing participant and discourse-related meanings.

The discussion in this paper points to a need for a much more fine-grained, socio-pragmatically sensitive and usage oriented sequential analysis of CS (see also Amuzu's discission of Ewe-English code alternation patterns in this volume). CS, like so-called style-shifting among monolinguals, is not epiphenomenal, but an important resource for negotiating social and interactional meanings (see also Chen's discussion of code alternation and identity in Hong Kong in this volume); the meanings, in turn, influence the structure of CS patterns. Research on CS must thus be embedded in a detailed analysis of a community's speech economy that takes into account the views of all local actors and is guided by both people's ideologies and actual practices. Using an ethnographic approach, such an analysis should determine the kinds of speech forms including mixed forms that are recognized by people, their salient or emblemic linguistic characteristics as well as their social functions and uses. Since we cannot assume simple correlations to exist between social functions and language use and structural makeup and functions, each instance has to be analyzed in detail using what Auer $(1984,1995)$ refers to as a sequential approach. Thus, comprehensive analysis of CS should

- be empirical and analyze each instance of CS separately within its context of occurrence.

- focus on situated language use.

- first identify the interactional functions and patterns of instances of CS before carrying out a structural analysis

- should examine each pattern or type of CS separately as the same principles may not hold across all types.

- explore how observable patterns of CS link to the negotiation of social identities and existing patterns of language use and ideologies of language.

\section{References}


Alby, Sophie and Migge, Bettina2007 Alternances codiques. In: Isabelle Léglise and Bettina Migge (eds.), Pratiques et attitudes linguistiques en Guyane: regards croisés, 49-72. Paris: Editions IRD.

Auer, Peter 1984 Bilingual conversations. Amsterdam: John Benjamins.

Auer, Peter 1995 The pragmatics of code-switching: a sequential approach. In: Lesley Milroy and Pieter Muysken (eds.), One speaker, two languages: Cross-disciplinary perspectices on codeswitching, 115-135. Cambridge: Cambridge University Press.

Bentahila, Abdelâli and Davies, Eirlys 1983 The syntax of Arabic-French code switching. Lingua 59: 301-30.

García, Orfelia 2009 Bilingual education in the $21^{\text {st }}$ century: A global perspective. Malden, MA: Wiley-Blackwell.

Blom, Jan P. and Gumperz, John 1972 Social meaning in linguistic structures: code-switching in Norway. In: John Gumperz and Dell Hymes (eds.), Directions in Sociolinguistics, 407-434. New York: Holt, Rinehart and Winston.

Myer-Scotton, Carol 1993a Social motivations for codeswitching: Evidence from Africa. Oxford: Clarendon Press.

Myer-Scotton, Carol 1993b Duelling Languages: Grammatical structure in codeswitching. Oxford: Clarendon Press.

Migge, Bettina 2011 Negotiating Social Identities on an Eastern Maroon Radio Show. Journal of Pragmatics 43(6): 1495-1511.

Migge, Bettina 2007 Code-switching and social identities in the Eastern Maroon community of Suriname and French Guiana. Journal of Sociolinguistics 11 (1): 53-72.

Migge, Bettina and Leglise, Isabelle 2013 Exploring Language in a Multilingual Context: Variation, Interaction and Ideology in Language Documentation. Cambridge: Cambridge University Press.

Migge, Bettina and Léglise, Isabelle 2011 On the emergence of new language varieties: The case of the Eastern Maroon Creole in French Guiana. In Lars Hinrichs and Joseph T. Farquharson (eds.), Variation in the Caribbean: From creole continua to individual agency, 207-229. Amsterdam: John Benjamins.

Migge, Bettina and Winford, Donald 2009 The origin and development of possibility in the creoles of Suriname. In Rachel Selbach, Hugo Cardoso and Margot van den Berg (eds), Gradual creolization, 129-153. Amsterdam: John Benjamins.

Muysken, Pieter 2004 Bilingual Speech: A typology of code-mixing. Cambridge: Cambridge University Press.

Nortier, Jacomine 1990 Dutch-Moroccan Arabic Code Switching among Maroccans in the Netherlands. Dordrecht: Foris.

Poplack, Shana and Meechan, Meechan 1995 Patterns of language mixture: nominal structure in Wolof-French and Fongbe-French bilingual discourse. In: Lesley Milroy and Pieter Muysken (eds.), One speaker, two languages: Cross-disciplinary perspectices on code-switching, 199-232. Cambridge: Cambridge University Press.

Spitulnik, Debra 1999 The language of the city: Town Bemba as urban hybridity. Journal of Linguistic Anthropology 8 (1): 30-59.

Winford, Donald 2003 An Introduction to contact linguistics. Malden, MA: Blackwell.

Zentella, Ana Celia 1994 Growing up Bilingual. Malden, MA: Blackwell. 